\title{
Hubungan Perilaku Self-Management Dengan Kadar Gula Darah Pada Pasien Diabetes Mellitus Tipe 2 Di Wilayah Kerja Puskesmas Pucang Sewu, Surabaya
}

\author{
The Relationship between Self-Management Behaviour and Blood Glucose \\ Level in Diabetes Mellitus Type 2 Patients in Pucang Sewu Health Center, \\ Surabaya
}

Milda Hidayah*1

\begin{abstract}
ABSTRAK
Latar Belakang: Diabetes Mellitus (DM) menjadi satu dari empat prioritas Penyakit Tidak Menular di dunia. Menurut IDF (International Diabetes Federation), peningkatan penyandang DM di Indonesia akan mengalami peningkatan dari 9,1 juta di tahun 2014 menjadi 14,1 juta di tahun 2035. Penyakit DM Tipe 2 dapat mempengaruhi kualitas hidup penderitanya dan dapat beresiko menimbulkan terjadinya komplikasi, masalah tersebut dapat dikendalikan salah satunya dengan menerapkan perilaku self-management terhadap penyakitnya.

Tujuan: Tujuan dari penelitian ini yaitu untuk mengetahui gambaran serta hubungan perilaku self-management (pengaturan pola makan, aktivitas fisik/olahraga, perawatan diri/kaki, kepatuhan konsumsi obat, dan monitoring gula darah) dengan kadar gula darah pada pasien Diabetes Mellitus Tipe 2 di wilayah kerja Puskesmas Pucang Sewu, Surabaya. Metode: Penelitian ini menggunakan desain studi observasional dengan menggunakan pendekatan cross sectional. Populasi pada penelitian ini adalah pasien rawat jalan yang menderita Diabetes Mellitus Tipe 2 di Puskesmas Pucang Sewu, Surabaya. Pengambilan data menggunakan teknik random sampling dan didapatkan 79 responden. Data penelitian didapatkan dengan menggunakan kuisioner SDSCA (The Summary of Diabates Self-Care Activities) yang telah dikembangkan oleh General Service Administration (GSA) Regulatory Information Servive Center (RISC). Analisis data menggunakan uji statistik chi-square.

Hasil: Hasil penelitian didapatkan bahwa sebagian responden memiliki tingkat self-management baik (59.5\%). Beberapa aspek seperti pengaturan pola makan, dan kepatuhan konsumsi obat, sebagian besar responden termasuk dalam kategori baik, namun pada aspek aktivitas fisik/olahraga, perawatan diri/kaki, dan monitoring gula darah masih dalam kategori kurang. Selain itu, sebagian besar responden memiliki kadar gula darah yang terkontrol (50,6\%).

Kesimpulan: Terdapat hubungan antara perilaku self-management dengan kadar gula darah pada pasien Diabetes Mellitus Tipe 2 di wilayah kerja Puskesmas Pucang Sewu Surabaya.
\end{abstract}

Kata Kunci: Self-management, Kadar Gula Darah, Diabetes Mellitus Tipe 2

\section{ABSTRACT}

Background: Diabetes Mellitus (DM) is one of the four priorities for Non-Contagious Diseases in the world. According to the IDF (International Diabetes Federation), people with Diabetes Mellitus in Indonesia will increase from 9.1 million in 2014 to 14.1 million in 2035. Diabetes Mellitus Type 2 can affect can affect the quality of life from the sufferers and can be at risk of causing complications, these problems can be solved by applying self-management to their disease.

Objectives: The purpose of this research is to describe the self-management behavior which consists of five aspects, that is settings of diet, physical activity/exercise, self/foot care, medication compliance, and monitoring of blood sugar in Type 2 Diabetes Mellitus patients at Pucang Sewu Health Center, Surabaya.

Methods: This research used observational study design using cross sectional approach. The population in this research were outpatients with Type 2 Diabetes Mellitus in Pucang Sewu Health Center, Surabaya. Data collection using random sampling technique and obtained 79 respondents. The research data was obtained using the SDSCA (The Summary of SelfCare Activities) questionnaire developed by the General Service Administration (GSA) Regulatory Information Servive Center (RISC).

Results: The research found that some respondents had a good level of self-management (59.5\%). In several aspects such as settings of diet, and medication compliance, most respondents were included in the good category, but in physical activity/ exercise, self/foot care, and monitoring of blood sugar aspect were still in the less category. In addition, most of the respondents had normal blood glucose levels (50.6\%). 
Conclusion: There is a relationship between self-management behavior with blood glucose levels in patients with Type 2 Diabetes Mellitus in Pucang Sewu Health Center, Surabaya.

Keywords: Self-management, Blood Glucose Levels, Type 2 Diabetes Mellitus.

\author{
*Koresponden: \\ milda.assegaf@gmail.com \\ 1Prodi S-1 Gizi Fakultas Kesehatan masyarakat, Universitas Airlangga, Kampus C Mulyorejo 66115, \\ Surabaya, Jawa Timur, Indonesia
}

\section{PENDAHULUAN}

Diabetes Mellitus (DM) menjadi satu dari empat prioritas Penyakit Tidak Menular di dunia. Berdasarkan data dari Riset Kesehatan Dasar (RISKESDAS) tahun $2018^{1}$, prevalensi kejadian diabetes di Indonesia yang telah terdiagnosis oleh dokter yaitu 1,5\%. Kejadian Diabetes Mellitus memiliki prevalensi tertinggi yaitu pada usia 55 tahun hingga 64 tahun, dan cenderung lebih tinggi terjadi pada perempuan ${ }^{1}$. WHO memprediksi adanya peningkatan jumlah penyandang DM di Indonesia sebanyak 2-3 kali lipat dari 8,4 juta orang di tahun 2000 menjadi sekitar 21,3 juta orang di tahun 2035². Sedangkan menurut IDF (International Diabetes Federation), peningkatan penyandang DM di Indonesia akan mengalami peningkatan dari 9,1 juta di tahun 2014 menjadi 14,1 juta di tahun $2035^{3}$.

Kemenkes RI tahun 2013 menyebutkan bahwa penyandang Diabetes Mellitus di Provinsi Jawa Timur terus mengalami peningkatan prevalensi 1,1 apabila dibandingkan dengan menggunakan hasil Riskesdas pada tahun 2007. Prevalensi kejadian diabetes di Jawa Timur menduduki peringkat 10 besar. Berdasarkan Riskesdas, jumlah penderita DM terus meningkat hingga mencapai angka 330.512 dari tahun 2007 hingga tahun $2013^{3}$.

Penyakit Diabetes Mellitus Tipe 2 merupakan penyakit gangguan metabolik yang dapat disebabkan kurangnya produksi insulin oleh sel $\beta$-pankreas atau tubuh tidak dapat mengoptimalkan penggunaan insulin. Insulin merupakan hormon yang berfungsi untuk mengendalikan keseimbangan kadar gula darah ${ }^{4}$. Diabetes Mellitus Tipe 2 dapat mempengaruhi kualitas hidup dari penderitanya dan dapat menimbulkan resiko terjadinya komplikasi. Penderita DM beresiko tinggi mengalami komplikasi berupa hipoglikemia, hiperglikemia, ketoasidosis, neuropathy yang meningkatkan resiko luka gangren yang berujung pada amputasi, retinopati yang berpotensial mengalami kebutaan, nefropati yang dapat berujung pada gagal ginjal ${ }^{5}$. Beberapa masalah yang dapat timbul pada pasien Diabetes Mellitus Tipe 2 ini dapat dikendalikan apabila pasien dapat menerapkan perilaku manajemen diri (self-management) pada penyakitnya. Selfmanagement diabetes dapat mencerminkan perilaku pasien secara sadar serta keinginan dari diri sendiri untuk mengendalikan penyakit Diabetes Mellitus Tipe $2^{6}$.

Self-management merupakan bagian integral dari pengendalian diabetes. Sebagai contoh, dalam banyak kasus pasien dianjurkan untuk dapat menjaga diet/ pola makan yang sehat serta olahraga yang tepat agar kadar glukosa tetap terkontrol7. Self- management dapat menggambarkan perilaku individu yang dilakukan secara sadar, bersifat universal, dan terbatas pada diri sendiri.
Self-management diabetes adalah tindakan yang dilakukan perorangan untuk mengontrol diabetes meliputi tindakan pengobatan dan pencegahan komplikasi. Beberapa aspek yang termasuk dalam selfmanagement diabetes yaitu pengaturan pola makan (diet), aktivitas fisik/olahraga, monitoring gula darah, kepatuhan konsumsi obat, serta perawatan diri/kaki ${ }^{8}$. Penerapan self-management yang optimal pada pasien diabetes dapat membantu dalam meningkatkan pencapaian tujuan dalam penatalaksanaan DM Tipe 2 . Oleh sebab itu, dibutuhkan kepatuhan/kedisiplinan dari pasien dalam menerapkan self-management diabetes guna meningkatkan kualitas hidup pasien?

Berdasarkan penelitian yang telah dilakukan sebelumnya oleh Linda (2017) ${ }^{9}$ di Puskesmas Srondol Semarang, didapatkan bahwa sebagian besar penderita Diabetes Mellitus disana telah mengetahui terkait pentingnya melakukan self-management diabetes seperti pengaturan diet (pola makan), aktivitas olahraga, perawatan kaki, konsumsi obat secara teratur, serta monitoring gula darah. Namun dalam penerapannya, sebagian besar pasien diabetes masih belum menjalankan beberapa aspek self-management secara optimal.

Penelitian lainnya yang telah dilakukan oleh (Putri, 2013) ${ }^{10}$ di Poliklinik DM RSUD Sumedang juga didapatkan hasil bahwa jumlah pasien dengan kategori self-management diabetes kurang sama dengan jumlah pasien dalam kategori self-management diabetes baik, serta jumlah yang sama antara pasien dengan kadar gula darah terkontrol dan tidak terkontrol, sehingga hasil dalam penelitian ini mengatakan bahwa terdapat hubungan antara perilaku self-management diabetes dengan kadar gula darah.

Berdasarkan data yang didapatkan oleh peneliti dari Puskesmas Pucang Sewu, jumlah pasien Diabetes Mellitus Tipe 2 di Puskesmas Pucang Sewu pata tahun 2018 yaitu sebanyak 362 pasien. Berdasarkan data yang didapatkan menunjukkan bahwa angka kejadian Diabetes Mellitus Tipe 2 banyak terjadi pada laki-laki dan perempuan pada usia 56 hingga 70 tahun.

Untuk membantu penanganan gula darah pada pasien dengan Diabetes Mellitus Tipe 2 di Puskesmas Pugcang Sewu, penelitian ini dilakukan oleh peneliti dengan tujuan mengetahui tingkat self-management serta hubungannya dengan kadar gula darah pada responden dengan usia 56-70 tahun (lansia).

\section{METODE}

Metode yang digunakan dalam penelitian ini adalah studi observasional, suatu penelitian analitik yang menggunakan pendekatan cross sectional, yaitu 
merupakan suatu metode yang digunakan untuk mempelajari dinamika korelasi antara faktor resiko dengan efek. Desain penelitian ini dapat menjelaskan tentang hubungan antara perilaku self-management diabetes dengan kadar gula darah pada pasien Diabetes Mellitus Tipe 2.

Dalam penelitian ini, yang termasuk dalam kelompok populasi adalah semua pasien rawat jalan yang menderita Diabetes Mellitus Tipe 2 di Puskesmas Pucang Sewu Kota Surabaya pada bulan April tahun 2019, dimana berdasarkan data Puskesmas Pucang Sewu terdapat 209 pasien DM yang datang pada bulan April. Kelompok sasaran dari penelitian ini yaitu responden laki-laki dan perempuan dengan usia 56 hingga 70 tahun yang menderita Diabetes Mellitus Tipe 2 di Puskesmas Pucang Sewu Surabaya. Besar sampel diperoleh dengan menggunakan rumus Slovin (Dahlan, 2013)11 dan didapatkan jumlah sampel sebesar 79 orang. Metode yang digunakan untuk menentukan sampel penelitian adalah dengan metode random sampling atau mengambil sampel secara acak. Terdapat beberapa kriteria inklusi yang digunakan yaitu, pasien Diabetes Mellitus Tipe 2 yang telah didiagnosis oleh dokter berdasarkan pemeriksaan kadar gula darah yang melebihi batas normal yaitu $\geq 200 \mathrm{mg} / \mathrm{dL} 2$ jam PP dan apabila gula darah puasa $\geq 126 \mathrm{mg} / \mathrm{dL}$ di Puskesmas Pucang Sewu Kota Surabaya, berjenis kelamin laki-laki maupun perempuan dengan usia 56 hingga 70 tahun, mampu melakukan aktifitas mandiri, dapat berkomunikasi dengan baik, serta bersedia untuk menjadi responden dalam penelitian dengan menandatangani form persetujuan.

Pengumpulan data terdiri data karakteristik responden (usia, jenis kelamin, tingkat pendidikan), yang didapatkan dengan wawancara menggunakan kuisioner. Tingkat self-management diabetes diperoleh melalui wawancara dengan menggunakan kuisioner SDSCA (The Summary of Diabates Self-Care Activities) yang telah dikembangkan oleh General Service Administration (GSA) Regulatory Information Servive Center (RISC) ${ }^{12}$ terdiri dari 17 poin pertanyaan yang berkaitan monitoring kadar gula darah. Metode dalam melakukan skoring pada kuesioner SDSCA yaitu menggunakan skala numerik, menggunakan jangka waktu penilaian 1 minggu yang diisi dengan rentang waktu 0 hingga 7 hari.

Terdapat dua jenis pertanyaan yaitu, favorable (dengan teknik skoring hari $0=0,1=1,2=2,3=3,4=$ $4,5=5,6=6$, dan $7=7$ ), unfavorable (dengan teknik skoring yag berlawanan dengan pertanyaan favorable). Total skor kemudian akan diuji normalitasnya dengan menggunakan uji Kolmogrov Smirnov (menentukan nilai mean/median yang akan digunakan sebagai Cut Off Point untuk menentukan tingkat self-management diabetes). Kadar gula darah responden diperoleh melalui pengukuran gula darah acak (GDA) dengan menggunakan One Call-Check Blood Glukose Meter yang kemudian hasil dari pengukuran GDA akan dikelompokkan menjadi dua kategori, yaitu responden dengan kadar gula darah yang terkontrol ( $<200 \mathrm{mg} / \mathrm{dl}$ ) dan responden dengan kadar gula darah yang tidak terkontrol $(\geq 200 \mathrm{mg} / \mathrm{dl})$. Teknik analisis data pada penelitian ini menggunakan uji chi square untuk mengetahui korelasi hubungan antara perilaku self- management diabetes dengan kadar gula darah. Penelitian ini telah lolos uji etik dengan Nomor: 1361KEPK yang dilakukan di komisi etik penelitian kesehatan Fakultas Keperawatan Universitas Airlangga.

\section{HASIL DAN PEMBAHASAN}

Pada hasil penelitian ini, didapatkan data karakteristik dari responden seperti usia, jenis kelamin, serta tingkat pendidikan yang dijabarkan pada Tabel 1 . Berdasarkan data yang didapatkan, diketahui bahwa dari 79 responden yang telah dikelompokkan menjadi tiga kategori, mayoritas responden merupakan lansia yang berusia 66-70 tahun (46,8\%). Responden dengan jenis kelamin perempuan (62\%) lebih banyak jika dibandingkan dengan responden laki-laki (38\%). Tingkat pendidikan responden berdasarkan jenjang pendidikan formal yang terakhir ditempuh, diketahui bahwa mayoritas adalah tamat SMA (40,5\%). Hal ini selaras dengan penelitian yang telah dilakukan oleh Linda $(2017)^{9}$, dimana mayoritas responden $(88,1 \%)$ menderita DM yaitu pada lansia dengan rentang usia $\geq 46$ tahun, sebanyak $63 \%$ responden dengan jenis kelamin perempuan, serta sebagian besar memiliki pendidikan terakhir SLTA/sederajat (32,6\%). Hasil dari penelitian lain yang telah dilakukan oleh Nita (2015) ${ }^{13}$, menyatakan bahwa lebih banyak pasien DM dengan usia $\geq 46$ tahun $(81,8 \%)$, dimana $49,8 \%$ diantaranya merupakan usia $\geq 56$ tahun, sebanayk $61,5 \%$ pasien memiliki jenis kelamin perempuan, serta lebih banyak pasien memiliki pendidikan terakhir di SMA yaitu $31,8 \%$. Hasil ini didukung oleh pernyataan Gusti \& Erna (2014) ${ }^{14}$ yang menyatakan bahwa penyakit DM sering dijumpai pada masyarakat usia lanjut, karena semakin bertambahnya usia seseorang, maka fungsi tubuh secara fisiologis akan mengalami penurunan (penurunan sekresi insulin) sehingga mengakibatkan kemampuan untuk mengendalikan glukosa darah kurang optimal. Menurut Irawan $(2010)^{15}$ wanita memiliki peluang lebih besar untuk mengidap diabetes salah satunya karena sindroma dari siklus bulanan (premenstrual syndrome), atau terjadinya pasca menopouse yang mengakibatkan distribusi dari lemak tubuh menjadi lebih mudah terakumulasi sebagai akibat dari proses hormonal yang terjadi.

Tingkat self-management diabetes responden dibedakan menjadi dua kategori yaitu, kurang apabila total skor $<$ mean/median, dan baik apabila total skor $\geq$ mean/median. Jumlah skor jawaban dari kuisioner di uji normalitasnya dengan aplikasi SPSS menggunakan uji Kolmogrov Smirnov, pada penelitian ini didapatkan hasil 0,910 (terdistribusi normal) sehingga menggunakan mean $(48,7)$ sebagai cut off point. Distribusi responden berdasarkan tingkat self-management diabetes dijabarkan pada Tabel 2. Didapatkan bahwa terdapat 47 responden $(59,5 \%)$ yang memiliki tingkat selfmanagement baik, sedangkan 32 responden (40,5\%) memiliki tingkat self-management kurang. Pada penelitian sebelumnya yang dilakukan oleh Reny $(2017)^{16}$ di wilayah kerja Puskesmas Tigo Baleh Kota Bukittinggi, didapatkan sebanyak $58,4 \%$ responden dengan DM memiliki tingkat self-management diabetes baik. 
Tabel 1. Distribusi Frekuensi Berdasarkan Karakteristik Responden di Puskesmas Pucang Sewu Tahun 2019.

\begin{tabular}{lcc}
\hline \multirow{2}{*}{ Variabel } & Jumlah & Persentase \\
\cline { 2 - 3 } & $\mathbf{n}$ & $\mathbf{\%}$ \\
\hline Usia & & \\
56-60 tahun & 28 & 35,5 \\
61-65 tahun & 14 & 17,7 \\
$66-70$ tahun & 37 & 46,8 \\
\hline Total & $\mathbf{7 9}$ & $\mathbf{1 0 0 , 0}$ \\
\hline Jenis Kelamin & & \\
Perempuan & 30 & 38,0 \\
Laki-laki & 49 & 62,0 \\
\hline Total & $\mathbf{7 9}$ & $\mathbf{1 0 0 . 0}$ \\
\hline Pendidikan Terakhir & & \\
Tidak Tamat SD & 12 & 15,2 \\
SD & 11 & 13,9 \\
SMP & 16 & 20,3 \\
SMA & 32 & 40,5 \\
PT & 8 & 10,1 \\
\hline Total & $\mathbf{7 9}$ & $\mathbf{1 0 0 . 0}$ \\
\hline
\end{tabular}

Tabel 2. Distribusi Responden Berdasarkan Tingkat SelfManagement Diabetes

\begin{tabular}{lcc}
\hline Kategori & Jumlah & Persentase \\
\cline { 2 - 3 } & $\mathbf{n}$ & $\%$ \\
\hline Kurang & 32 & 40,5 \\
Baik & 47 & 59,5 \\
\hline Total & $\mathbf{7 9}$ & $\mathbf{1 0 0 . 0}$ \\
\hline
\end{tabular}

Self-management diabetes pada penelitian ini terdiri dari lima aspek yaitu pengaturan diet/pola makan, aktivitas fisik/olahraga, perawatan diri/kaki, kepatuhan konsumsi obat, serta monitoring kadar gula darah.

Distribusi status responden berdasarkan lima aspek dari self-management diabetes dijabarkan pada Tabel 3. Hasil penelitian menunjukkan bahwa sebagian besar responden yang memiliki status self-management diabetes yang baik yaitu pada aspek pengaturan pola makan $(51,9 \%)$, dan kepatuhan konsumsi obat (81\%). Sedangkan pada aspek aktivitas fisik/olahraga, perawatan diri/kaki, serta monitoring kadar gula darah, sebagian besar responden memiliki status selfmanagement diabetes yang kurang yaitu masing-masing $54,4 \%, 84,4 \%, 82,3 \%$. Hasil ini sedikit berlawanan dengan penelitian yang telah dilakukan oleh Putri $(2013)^{10}$ di Poliklinik DM RSUD Sumedang, dimana tingkat self-management diabetes yang termasuk kurang yaitu dalam aspek monitoring gula darah (74,5\%), sedangkan untuk aspek lainnya termasuk dalam kategori baik. Pada penelitian yang dilakukan Linda $(2017)^{9}$, mayoritas responden memiliki tingkat self-management diabetes yang baik pada seluruh aspek. Perbedaan ini dapat timbul karena faktor-faktor yang berbeda pada setiap individu, seperti kondisi responden yang merupakan kelompok lansia yang mengakibatkan berkurangnya kemampuan untuk melakukan aktivitas fisik, dapat disebabkan karena kondisi fisik ataupun kondisi lingkungan yang tidak mendukung ${ }^{17}$. Kondisi responden yang tidak memiliki riwayat luka pada kaki maupun anggota tubuh lainnya membuat responden merasa tidak perlu untuk melakukan perawatan pada kakinya. Selain itu, pada penelitian ini mayoritas responden merupakan lansia yang hidup sendiri maupun hanya berdua dengan pasangan sehingga kurangnya dukungan dari keluarga juga dapat mengakibatkan rendahnya kesadaran responden untuk melakukan perawatan kaki. Dukungan keluarga dapat diberikan oleh orangtua, suami, istri, anak maupun saudara dekat pasien lainnya, dukungan yang diberikan dapat berupa informasi, perhatian dalam bentuk tingkah laku maupun materi yang dapat menjadikan pasien merasa disayangi dan dicintai ${ }^{18}$. Pada penelitian ini, mayoritas responden melakukan monitoring gula darah atas inisiatif dokter, bukan kesadaran diri sendiri, sehingga pasien merasa perlu melakukan pengecekan gula darah apabila dianjurkan oleh dokter atau ketika kondisi tubuhnya tidak normal/sakit.

Tabel 3. Distribusi Berdasarkan Tingkat SelfManagement Diabetes pada Setiap Aspek

\begin{tabular}{lcc}
\hline Variabel Self-Management & Jumlah & Persentase \\
\cline { 2 - 3 } Diabetes & $\mathbf{n}$ & $\%$ \\
\hline $\begin{array}{l}\text { Pengaturan Pola Makan } \\
\text { Kurang }\end{array}$ & 38 & 48,1 \\
$\quad$ Baik & 41 & 51,9 \\
\hline Total & $\mathbf{7 9}$ & $\mathbf{1 0 0 . 0}$ \\
\hline Aktivitas Fisik/Olahraga & & \\
$\quad$ Kurang & 43 & 54,4 \\
$\quad$ Baik & 36 & 45,6 \\
\hline Total & $\mathbf{7 9}$ & $\mathbf{1 0 0 . 0}$ \\
\hline Perawatan Diri/Kaki & & \\
$\quad$ Kurang & 67 & 84,4 \\
$\quad$ Baik & 12 & 15,2 \\
\hline Total & $\mathbf{7 9}$ & $\mathbf{1 0 0 . 0}$ \\
\hline Kepatuhan Konsumsi Obat & & \\
$\quad$ Kurang & 15 & 19,0 \\
$\quad$ Baik & 64 & 81,0 \\
\hline Total & $\mathbf{7 9}$ & $\mathbf{1 0 0 . 0}$ \\
\hline Monitoring Gula Darah & & \\
$\quad$ Kurang & 65 & 82,3 \\
$\quad$ Baik & 14 & 17,7 \\
\hline Total & $\mathbf{7 9}$ & $\mathbf{1 0 0 . 0}$ \\
\hline
\end{tabular}

Tabel 4 menunjukkan distribusi frekuensi skor untuk setiap pertanyaan dari lima aspek selfmanagement diabetes. Pada aspek pengaturan pola makan, sebagian besar responden tidak pernah melakukan perencanaan diet/pola makan $(79,7 \%)$ dalam satu minggu terakhir, namun sebagian besar responden selalu mengkonsumsi buah dan sayur (62\%), tidak pernah mengkonsumsi makanan berlemak tinggi $(49,4 \%)$, mengatur konsumsi karbohidrat $(79,7 \%)$, dan mengikuti pola makan sehat $(49,4 \%)$, serta tidak pernah mengkonsumsi snack yang banyak mengandung gula $(41,8 \%)$ selama satu minggu terakhir. Pada aspek aktivitas fisik/olahraga, sebagian besar responden selalu 
Tabel 4. Distribusi Frekuensi Skor Kuisioner Self-Management Diabetes

\begin{tabular}{|c|c|c|c|c|c|c|c|c|}
\hline \multirow{2}{*}{ Pertanyaan } & \multicolumn{8}{|c|}{ Jawaban Dalam Hari } \\
\hline & 0 & 1 & 2 & 3 & 4 & 5 & 6 & 7 \\
\hline \multicolumn{9}{|l|}{ Pengaturan Pola Makan } \\
\hline Mengatur pola makan/diet & $63(79,7 \%)$ & 0 & 0 & $2(2,5 \%)$ & $1(1,3)$ & 0 & 0 & $13(16,5 \%)$ \\
\hline Makan buah dan sayuran & $5(6,3 \%)$ & $1(1,3 \%)$ & $6(7,6 \%)$ & $9(11,4 \%)$ & $6(7,6 \%)$ & $3(3,8 \%)$ & 0 & $49(62,0 \%)$ \\
\hline $\begin{array}{l}\text { Mengkonsumsi makanan } \\
\text { berlemak tinggi atau produk } \\
\text { olahan susu }\end{array}$ & $39(49,4 \%)$ & $10(12,7 \%)$ & $15(19,0 \%)$ & $7(8,9 \%)$ & $3(3,8 \%)$ & $1(1,3 \%)$ & 0 & $4(5,1 \%)$ \\
\hline Mengatur konsumsi karbohidrat & $13(16,5 \%)$ & 0 & 0 & $1(1,3 \%)$ & $2(2,5 \%)$ & 0 & 0 & $63(79,7 \%)$ \\
\hline Mengikuti pola makan sehat & $17(21,5 \%)$ & 0 & $7(8,9 \%)$ & $6(7,6 \%)$ & $7(8,9 \%)$ & $3(3,8 \%)$ & 0 & $39(49,4 \%)$ \\
\hline $\begin{array}{l}\text { Konsumsi makanan selingan yang } \\
\text { mengandung gula }\end{array}$ & $33(41,8 \%)$ & $8(10,1 \%)$ & $9(11,4 \%)$ & $6(7,6 \%)$ & $\begin{array}{c}1 \\
(1,3 \%)\end{array}$ & 0 & 0 & $\begin{array}{c}22 \\
(27,8 \%)\end{array}$ \\
\hline \multicolumn{9}{|l|}{ Aktivitas Fisik/Olahraga } \\
\hline Melakukan aktivitas fisik & $21(26,6 \%)$ & 0 & $3(3,8 \%)$ & $1(1,3)$ & 0 & 0 & $1(1,3)$ & $53(67,1 \%)$ \\
\hline Mengikuti sesi latihan & $37(46,8 \%)$ & $3(3,8 \%)$ & $8(10,1 \%)$ & $9(11,4 \%)$ & $2(2,5 \%)$ & $2(2,5 \%)$ & 0 & $18(22,8 \%)$ \\
\hline \multicolumn{9}{|l|}{ khusus/olahraga } \\
\hline \multicolumn{9}{|l|}{ Perawatan Diri/Kaki } \\
\hline Memeriksa kaki & $76(96,2 \%)$ & 0 & 0 & 0 & 0 & 0 & 0 & $3(3,8 \%)$ \\
\hline $\begin{array}{l}\text { Memeriksa bagian dalam sepatu } \\
\text { sebelum digunakan }\end{array}$ & $79(100 \%)$ & 0 & 0 & 0 & 0 & 0 & 0 & 0 \\
\hline $\begin{array}{l}\text { Mengeringkan sela jari setelah } \\
\text { dicuci }\end{array}$ & $71(89,9 \%)$ & $1(1,3 \%)$ & $1(1,3 \%)$ & 0 & 0 & 0 & 0 & $6(7,6 \%)$ \\
\hline $\begin{array}{l}\text { Menggunakan alas kaki saat } \\
\text { keluar rumah }\end{array}$ & 0 & 0 & 0 & 0 & 0 & 0 & 0 & $79(100 \%)$ \\
\hline $\begin{array}{l}\text { Menggunakan pelembab pada } \\
\text { kaki }\end{array}$ & $71(89,9 \%)$ & $3(3,8 \%)$ & 0 & $1(1,3 \%)$ & 0 & 0 & 0 & $4(5,1 \%)$ \\
\hline \multicolumn{9}{|l|}{ Kepatuhan Konsumsi Obat } \\
\hline $\begin{array}{l}\text { Penggunaan obat diabetes yang } \\
\text { disarankan }\end{array}$ & $8(10,1 \%)$ & 0 & $4(5,1 \%)$ & 0 & $2(2,5 \%)$ & $2(2,5 \%)$ & $1(1,3)$ & $53(67,1 \%)$ \\
\hline Penggunaan insulin & $78(98,7 \%)$ & 0 & 0 & 0 & 0 & $1(1,3)$ & 0 & 0 \\
\hline \multicolumn{9}{|l|}{ Monitoring Gula Darah } \\
\hline $\begin{array}{l}\text { Mengecek gula darah yang } \\
\text { disarankan tenaga kesehatan }\end{array}$ & $65(82,3 \%)$ & $14(17,7 \%)$ & 0 & 0 & 0 & 0 & 0 & 0 \\
\hline $\begin{array}{l}\text { Mengecek gula darah yang } \\
\text { menggunakan insulin }\end{array}$ & $78(98,7 \%)$ & $1(1,3 \%)$ & 0 & 0 & 0 & 0 & 0 & 0 \\
\hline
\end{tabular}

melakukan aktivitas fisik ringan dengan waktu minimum 30 menit $(67,1 \%)$, namun tidak pernah melakukan aktivitas fisik khusus/olahraga (46,8\%) dalam satu minggu terakhir. Pada aspek perawatan diri/kaki, sebagian besar responden tidak pernah memeriksa kaki (96,2\%), mengecek bagian dalam sepatu sebelum digunakan (100\%), mengeringkan sela jari dengan handuk setelah dicuci $(89,9 \%)$, dan mengaplikasikan pelembab pada sela jari $(89,9 \%)$ dalam satu minggu terakhir, namun seluruh responden selalu menggunakan alas kaki saat pergi keluar rumah (100\%) dalam satu minggu terakhir.

Pada aspek kepatuhan konsumsi obat, sebagian besar responden tidak pernah menggunakan insulin $(98,7 \%)$, namun responden selalu mengonsumsi obat diabetes yang disarankan oleh dokter $(67,1 \%)$ dalam satu minggu terakhir. Pada aspek monitoring gula darah, sebagian besar responden yang menggunakan insulin $(82,3 \%)$ maupun tidak menngunakan insulin $(98,7 \%)$ tidak pernah melakukan cek gula darah dalam satu minggu terakhir.

Data kadar gula darah acak responden dijabarkan pada Tabel 5, menunjukkan bahwa jumlah responden berdasarkan hasil pengukuran gula darah yaitu, terdapat 40 responden $(50,6 \%)$ yang termasuk dalam kategori terkontrol, dan 39 responden $(49,4 \%)$ termasuk dalam kategori tidak terkontrol.

Tabel 5. Distribusi Frekuensi Berdasarkan Kadar Gula Darah Responden di Puskesmas Pucang Sewu Tahun 2019.

\begin{tabular}{lcc}
\hline Gula Darah Acak & Jumlah & Persentase \\
\cline { 2 - 3 } & $\mathbf{n}$ & $\mathbf{\%}$ \\
\hline Terkontrol & 40 & 50,6 \\
Tidak Terkontrol & 39 & 49,4 \\
\hline Total & $\mathbf{7 9}$ & $\mathbf{1 0 0 , 0}$ \\
\hline
\end{tabular}

Tabel 6 menunjukkan bahwa mayoritas responden yang memiliki status self-management diabetes kurang, memiliki status kadar gula darah yang tidak terkontrol $(31,6 \%)$, sedangkan untuk responden dengan status self-management diabetes baik, sebagian besar memiliki status kadar gula darah yang normal/terkontrol $(41,8 \%)$. Penelitian lain yang dilakukan oleh Nunung (2016) ${ }^{19}$ di RSUD dr. Zainoel Abidin Banda Aceh, menyatakan bahwa mayoritas pasien dengan self-management diabetes baik memiliki kadar gula darah yang normal $(68,7 \%)$, sedangkan pasien dengan self-management diabetes kurang, sebagian besar memiliki kadar gula darah yang tidak normal (68.7\%). 
Tabel 6. Distribusi Responden Berdasarkan Status Self-Management Diabetes dan Status Kadar Gula Darah di Puskesmas Pucang Sewu Tahun 2019.

\begin{tabular}{|c|c|c|c|c|c|c|c|}
\hline \multirow{3}{*}{ Status Self-management diabetes } & \multicolumn{4}{|c|}{ Status kadar gula darah } & \multirow{3}{*}{$\begin{array}{c}\text { Total } \\
\text { Frekuensi }\end{array}$} & \multirow{3}{*}{$p$ value } & \multirow{3}{*}{ PR } \\
\hline & \multicolumn{2}{|c|}{ Tidak Terkontrol } & \multicolumn{2}{|c|}{ Terkontrol } & & & \\
\hline & $\mathrm{n}$ & $\%$ & $\mathrm{n}$ & $\%$ & & & \\
\hline Kurang & 25 & 31,6 & 7 & 8,9 & 32 & & \\
\hline Baik & 14 & 17,7 & 33 & 41,8 & 47 & 0 & 1,21 \\
\hline Total & 39 & 49,4 & 40 & 50,6 & 79 & & \\
\hline
\end{tabular}

Tabel 7. Distribusi Responden Berdasarkan Aspek Status Self-Management Diabetes dan Status Kadar Gula Darah di Puskesmas Pucang Sewu Tahun 2019.

\begin{tabular}{|c|c|c|c|c|c|c|c|}
\hline \multirow{3}{*}{ Pengaturan Pola Makan } & \multicolumn{4}{|c|}{ Status kadar gula darah } & \multirow{3}{*}{$\begin{array}{c}\text { Total } \\
\text { Frekuensi }\end{array}$} & \multirow{3}{*}{ p value } & \multirow{3}{*}{ PR } \\
\hline & \multicolumn{2}{|c|}{ Tidak Terkontrol } & \multicolumn{2}{|c|}{ Terkontrol } & & & \\
\hline & $\mathbf{n}$ & $\%$ & $\mathbf{n}$ & $\%$ & & & \\
\hline \multicolumn{8}{|l|}{ Pengaturan Pola Makan } \\
\hline Kurang & 26 & 32,9 & 12 & 15,2 & 41 & 0,001 & 2,15 \\
\hline Baik & 13 & 16,5 & 28 & 35,4 & & & \\
\hline \multicolumn{8}{|l|}{ Aktivitas Fisik/Olahraga } \\
\hline Kurang & 26 & 32,9 & 17 & 21,5 & 43 & 0,031 & 2,38 \\
\hline Baik & 13 & 16,5 & 23 & 29,1 & 36 & & \\
\hline \multicolumn{8}{|l|}{ Perawatan Diri/Kaki } \\
\hline Kurang & 37 & 46,8 & 30 & 38,0 & 67 & 0,014 & 103,2 \\
\hline Baik & 2 & 2,5 & 10 & 12,7 & 12 & & \\
\hline \multicolumn{8}{|l|}{ Kepatuhan Minum Obat } \\
\hline Kurang & 12 & 15,2 & 3 & 3,8 & 15 & 0,008 & 0,10 \\
\hline Baik & 27 & 34,2 & 37 & 46,8 & 64 & & \\
\hline \multicolumn{8}{|l|}{ Monitoring Kadar Gula Darah } \\
\hline Kurang & 33 & 41,8 & 32 & 40,5 & 65 & 0,591 & 25,5 \\
\hline Baik & 6 & 7,6 & 8 & 10,1 & 14 & & \\
\hline
\end{tabular}

Berdasarkan uji hubungan menggunakan chi square, didapatkan nilai $p$ value lebih kecil dari 0,05 , sehingga HO ditolak yang artinya bahwa terdapat hubungan antara perilaku self-management diabetes (yang menggambarkan status self-management diabetes) dengan kadar gula darah pasien Diabetes Mellitus Tipe 2. Analisis besar resiko diperoleh nilai PR (Prevalen Rasio) sebesar 1,21 yang artinya bahwa perilaku self-management diabetes yang kurang merupakan faktor resiko/ faktor determinan (faktor penyebab) terjadinya regulasi kadar gula darah yang tidak terkontrol. Hasil ini selaras dengan penelitian Nunung $(2016)^{19}$ yang menjelaskan bahwa terdapat hubungan antara self-management pasien Diabetes Mellitus Tipe 2 dengan kadar gula darah. Masyarakat dengan penyakit Diabetes Mellitus dianjurkan untuk dapat menjaga diet/pola makan, pemilihan aktivitas fisik/olahraga yang tepat, serta kepatuhan dalam menjalankan self-management diabetes agar kadar glukosa dapat tetap terkontrol ${ }^{7}$. Keberhasilan penatalaksanaan pasien Diabetes Mellitus Tipe 2 dapat dipengaruhi oleh kepatuhan pasien dalam menjalankan/menerapkan self-management terhadap penyakit DM Tipe $2^{8}$. Sedangkan untuk uji hubungan antara setiap aspek pada self-management diabetes dengan kadar gula darah dijabarkan pada Tabel 7.

Beberapa aspek seperti pengaturan pola makan, aktivitas fisik/olahraga, perawatan diri/kaki, dan kepatuhan minum obat memiliki nilai $p$ value lebih kecil dari 0,05 yang berarti bahwa empat aspek tersebut memiliki hubungan yang signifikan terhadap kadar gula darah, sedangkan pada aspek monitoring kadar gula darah tidak memiliki hubungan signifikan terhadap kadar gula darah. Hasil uji PR didapatkan bahwa hanya aspek kepatuhan minum obat yang merupakan faktor proteksi/penghambat $(P R<1)$ terjadinya regulasi kadar gula darah yang tidak terkontrol, dan empat aspek lainnya merupakan faktor resiko/ faktor determinan (faktor penyebab) terjadinya regulasi kadar gula darah yang tidak terkontrol.

Hal ini dapat disebabkan karena beberapa aspek dalam self-management diabetes dapat mempengaruhi kadar gula darah, seperti pengaturan pola makan yang berfungsi untuk menekan asupan karbohidrat, lemak yang berlebih agar kadar glukosa dalam darah dapat seimbang dengan kerja hormon insulin, aktivitas fisik/olahraga membantu mengontrol berat badan, sehingga glukosa dalam darah dibakar menjadi energi dalam tubuh yang menyebabkan sel-sel tubuh menjadi lebih sensitif terhadap insulin, perawatan diri/kaki dapat membantu menjaga kesehatan kaki serta meminimalisir resiko timbulnya luka kaki pada pasien DM yang dapat berkembang menjadi ulkus diabetik,

kandungan yang terdapat pada obat anti-diabetik seperti jenis obat derivate sulvunilurea dapat membantu penyerapan glukosa dalam darah serta jenis biguanida untuk menghambat proses pembentukan glukosa, 
sedangkan perilaku monitoring gula darah rutin dapat digunakan sebagai tolak ukur untuk melihat keberhasilan dari penanganan diabetes yang telah dilakukan, dan dapat dijadikan sebagai motivasi untuk dapat menjaga kadar gula darah agar tetap dalam batas normal.

\section{KESIMPULAN}

Hasil penelitian ini menunjukkan bahwa penerapan perilaku self-management diabetes dapat mempengaruhi kadar gula darah pada pasien Diabetes Mellitus Tipe 2 di Wilayah Kerja Puskesmas Pucang Sewu Surabaya. Mayoritas responden memiliki tingkat selfmanagement diabetes yang baik namun dalam penatalaksanaannya masih terdapat beberapa aspek yang tergolong dalam kategori kurang.

\section{ACKNOWLEDGEMENT}

Peneliti mengucapkan terima kasih kepada Kepala Puskesmas Pucang Sewu, Surabaya yang telah memberikan izin sehingga penelitian ini dapat dilaksanakan, seluruh staff puskesmas yang telah membantu jalannya penelitian, seluruh responden yang bersedia dalam mengikuti setiap prosedur penelitian, serta seluruh staff pengajar program Studi S1 Gizi Fakultas Kesehatan Masyarakat Universitas Airlangga atas bimbingan serta dukungan yang telah diberikan.

\section{REFERENSI}

1. Kementerian Kesehatan. Hasil Utama Riskesdas 2018. Hasil Utama Riskesdas Tentang Prevalensi Diabetes Melitus di Indonesia 2018 (2018). doi:1 Desember 2013

2. Perkeni. Pengelolaan dan Pencegahan Diabetes Melitus Tipe 2 di Indonesia 2015. (2015).

3. Pusat Data Dan Informasi Kementerian Kesehatan RI. Situasi dan Analisis Diabetes. American Journal of Medical Genetics, Part A 161, (2014).

4. World Health Organization 2011. World Health Statistics. (2011).

5. American Diabetes Association. Standards of Medical Care in Diabetes--2009. Diabetes Care 32, S13-S61 (2009).

6. Funnel, M. M. et al. National Standards for Diabetes Self-Management Education. 31, (2008).

7. Sugiyama, T., Steers, W. N., Wenger, N. S., Duru, O. K. \& Mangione, C. M. Effect of a community- based diabetes self-management empowerment program on mental health-related quality of life: a causal mediation analysis from a randomized controlled trial. BMC Health Serv. Res. 15, 1-9 (2015).

8. Huang, M., Parker, M. J. \& Stubbe, J. Choosing the right metal: Case studies of class I ribonucleotide reductases. J. Biol. Chem. 289, 28104-28111 (2014).

9. Putri, L. R. Gambaran Self Care Penderita Diabetes Melitus (DM) Di Wilayah Kerja Puskesmas Srondol Semarang. (2017).

10. Putri, D. S. R., Yudianto, K. \& Kurniawan, T. Perilaku Self-Management Pasien Diabetes Melitus (DM). 1, 30 (2013).

11. Dahlan, M. S. Besar Sampel dan Cara Pengambilan Sampel dalam Penelitian Kedokteran dan Kesehatan. Salemba Medika (2013).

12. Kamradt, M. et al. Assessing self-management in patients with diabetes mellitus type 2 in Germany: Validation of a German version of the Summary of Diabetes Self-Care Activities measure (SDSCA-G). Health Qual. Life Outcomes 12, 1-10 (2014).

13. Rachmawati, N. Gambaran Kontrol Dan Kadar Gula Darah Pada Pasien Diabetes Melitus Di Poliklinik Penyakit Dalam RSJ Prof. Dr. Soerojo Magelang. 01, 1-8 (2015).

14. Jelantik, I. G. M. G. \& Haryati, E. Hubungan Faktor Risiko Umur, Jenis Kelamin, Kegemukan dan Hipertensi Dengan Kejadian Diabetes Melitus Tipe II di Wilayah Kerja Puskesmas Mataram. Media Bina Ilmiah39 8, 39-44 (2014).

15. Irawan, D. Prevalensi Dan Faktor Risiko Kejadian Diabetes Mellitus Tipe 2 Di Daerah Urban Indonesia (Analisa Data Sekunder RISKESDAS 2007). (2010).

16. Chaidir, R., Wahyuni, A. S. \& Furkhani, D. W. Hubungan Self Care Dengan Kualitas Hidup Pasien Diabetes Melitus. J. Endur. 2, 132 (2017).

17. Kurnianto P, D. Menjaga Kesehatan Di Usia Lanjut. J. Olahraga Prestasi 11, 19-30 (2015).

18. Ali \& Zaidin. Pengantar Keperawatan Keluarga. EGC 1, (2009).

19. Mulyani, N. S. Hubungan Self Management Pasien Diabetes Mellitus Tipe II Dengan Kadar Gula Darah Di Rumah Sakit Kota Banda Aceh. Politek. Kesehat. Kementeri. Kesehat. Aceh 3, 5663 (2016). 